Article

\title{
What Makes an Old Market Sustainable? An Empirical Analysis on the Economic and Leisure Performances of Traditional Retail Markets in Seoul
}

\author{
Yun-Myong Yi ${ }^{1}$ (i) and Tae-Hyoung Tommy Gim ${ }^{1,2,3, *}$ \\ 1 Environmental Planning Institute, Graduate School of Environmental Studies, Seoul National University, \\ Seoul 08826, Korea; yunnis@snu.ac.kr \\ 2 Department of Environmental Planning, Graduate School of Environmental Studies, Seoul National \\ University, Seoul 08826, Korea \\ 3 Interdisciplinary Program in Landscape Architecture, Seoul National University, Seoul 08826, Korea \\ * Correspondence: taehyoung.gim@snu.ac.kr; Tel.: +82-2-880-1459; Fax: +82-2-871-8847
}

Received: 15 April 2018; Accepted: 22 May 2018; Published: 29 May 2018

\begin{abstract}
Traditional retail markets have long been the center for urban vitality, yet they have been under threat of advancing superstores run by corporate retailers. Studies have attempted to identify the competitiveness of the markets, but empirical evidence is not sufficient for presenting which factors contribute to the maintenance of a traditional market's economic vitality. In South Korea, urban policies have been directed to revitalizing the markets, but their effectiveness has been questioned. This study aims to fill this void by examining traditional markets in Seoul with multiple regression on (1) the revenue and (2) the volume of customers and with negative binomial regression on (3) the popularity measured by the number of blog posts on the markets. Using a comprehensive set of variables, this paper finds that investments in physical infrastructure $(p<0.000)$ and organizational/operational capacities $(p<0.008$ and $p<0.094)$ make a significant contribution to the economic vitality. Among product categories, the ratios of perishable food stores were found to be significant $(p<0.000)$ as well as those of food shops and vendors $(p<0.030)$. On the other hand, extending convenient facilities and anchor stores would reduce the revenue in the short term. In addition, traditional markets that are recognized as popular destinations may not necessarily be profitable. In this vein, attention should be paid to this mismatch when a strategy is deliberated to transform a market into a tourist attraction.
\end{abstract}

Keywords: traditional retail market; marketplace; economic vitality; urban regeneration; blogs; linear regression; negative binomial regression; Seoul

\section{Introduction}

Located at the center of residential neighborhoods and old commercial districts, traditional retail markets, also known as wet markets, have been economic transaction hubs and the center for social activities where people gathered, socialized, and exchanged goods and information [1-3]. In modern society, however, retail functions are mainly assumed by larger, more agglomerated forms than traditional markets; they are often run by corporate international retailers with highly competitive distribution systems. This retail modernization, featured by one-stop shopping at superstores, shopping malls, and large-scale hypermarkets, allowed a significant cut in costs and prices for both customers and retailers [4]. These modernized retail outlets, however, have expanded at the expense of the existing retailers and small businesses including traditional markets [5-8].

The above retail transition also occurred in South Korea. Traditional markets have been losing their competitiveness against corporate retailers since the 1960s $[9,10]$. Such a pattern has been considerably 
accelerated since the national financial crisis in the late 1990s when the International Monetary Fund (IMF) Foreign Investment Promotion Act was implemented. The act allowed superstores to locate in downtown areas. Since the 2000s, competitions among the superstores have made traditional retail stores and small businesses further lose their shares in the retail industry [11]. Moreover, as the point of retail purchase has increasingly moved from the physical to the virtual space, these corporate retailers launched online shopping malls for their own sake. Consequently, such excessive advancement of the large international retail formats raised concerns over the existence of traditional retail markets and small businesses. Conflicts have been raised between traditional markets and corporate retailers, which is currently one of the most controversial social issues in South Korea.

For more than a decade, the Ministry of Small and Medium Business Administration launched various policies and programs to modernize the physical and operational (functional) aspects of traditional markets and to facilitate their economic sustainability [12,13]. Accordingly, researchers have assessed the effectiveness and feasibility of the policies/programs and paid greater attention to the traditional retail markets to identify their competitiveness in the present society [14-16]. Such an academic attempt identified several determinants of the economic competitiveness such as humanity, kindness, festiveness, and sociality [17-20] that have been empirically confirmed in the international context $[1,2,21,22]$. On the other hand, studies have also recognized that the economic vitality is a prerequisite for such socio-cultural attractiveness of a traditional market to become viable [1,23]. In spite of this recognition, not many studies have been found to test and examine the factors enabling (and sustaining) the economic performance of traditional markets.

At this juncture, this study aims to explore the effects of physical, operational/organizational and environmental characteristics of a traditional retail market on its retail performance. Specifically, this study aims to discover which factors make the traditional markets economically successful and culturally attractive (and popular) among leisure visitors. Among the physical, operative/organizations, product, and environmental components of a market, this study aims to discover which specific attributes play a significant role on each performance measure. Subsequently, this study investigates the factors influencing the economic performances of the traditional retail markets and finds how they differ from those related to the popularity of the markets.

Despite an increasing attention on the topic in academia, only a small number of studies took empirical approaches by conducting analyses of quantitative data on multiple markets $[13,14,24]$ while the other majority of previous studies relied predominantly on case studies examining a limited number of markets; they frequently used qualitative interviews or participant observations $[1,9,19$, $21,25,26]$ or the results of a second-hand customer survey in discovering the competitiveness of the traditional markets in modern society $[6,17,27-30]$. Likewise, the effectiveness of public policies to regenerate declined markets has also been studied in large part with customer survey data from a few sites [31-33]. Although our understanding about the traditional markets and the effects of the public policies have expanded from the previous studies, it is hard to draw generalized knowledge from them. In addition, the outcomes and the measurement indicators differ by studies; it is unclear whether the results are applicable for multiple cases of traditional markets located in different contexts. Without due empirical evidence based on a standardized evaluation of multiple subjects, case studies could not reach a consensus on what was required to make a traditional market competitive and economically sustainable [34]. In addition, the characteristics of traditional markets have not been investigated in detail (e.g., products sold, scale, physical conditions, and operative/service conditions) despite growing attention being paid to their socio-cultural importance and contribution to the local economy $[2,25,35]$.

Examining a total of 131 traditional retail markets in Seoul, the national capital with 11 million residents (2017), this study employs three gross performance measures of the traditional markets: (1) annual revenue; (2) annual customer volume; and (3) number of blog posts uploaded on Internet portals as a measure of a traditional market's popularity. Since a retail store's level of performance is affected by multiple factors, for example, product type, location, organizational capacity, 
convenience, and physical building conditions [24,36], this study chose to conduct multivariate analysis with a multiple number of cases. In addition to the characteristics of the markets on the three performance indicators, this paper classified environmental variables in four different geographical units (specifically, market inside, 500-m buffered zone, neighborhood, and district) from which one can possibly identify appropriate administrative units at which a policy tool should be exerted. In geography and planning, the spatial range of the effect of a variable is a long-standing topic - particularly in relation to the modifiable areal unit problem (MAUP) and boundary problem -in designing urban policies (e.g., transportation impact fees and community grant programs) [37,38]. For example, the location of a new local grocery store may be expected to have a smaller range of effect than that of a department store.

\section{Literature Review}

The retail performance, including the level of customer satisfaction, is determined by a variety of factors. An empirical case study on a public market in a small Korean city, Gunsan, noted that economic revitalization of a traditional market requires a balanced approach encompassing such factors as a market's facility and product line as well as its operational capacity and business competitors in the district [39]. Similarly, Jeon [24] recognized that retail competence is defined by product quality and assortment, the image of stores, location, physical components, and customer service. The study then acknowledged that traditional markets are behind all these aspects relative to other modernized retails. The Small Enterprise and Market Service (SEMAS) employs five components in assessing the vitality of a traditional market [36]: merchants' service capacity and store conditions and the market's environmental characteristics, products, and other infrastructure. Specifically, the environmental characteristics of a traditional market are captured with multiple indicators including transportation accessibility, parking, convenient facilities, advertisements, and building conditions.

Discussing a new paradigm for traditional markets, scholars $[27,29,39]$ have often criticized initial efforts made at various governmental levels for the modernization of the physical components of the markets (e.g., roofs, alleys, gates, advertisement facilities, and parking lots). They argued that such standardized public programs resulted in the loss of distinctive characteristics conveyed in traditional markets. For example, Kim and Kim [39] found that public investments have been disproportionately and sporadically made on facility management and accordingly recommended that soft components such as product lines and brands need to be developed for traditional markets. From the same perspective, other scholars (and some policy makers) [15,27,39-42] argued that traditional markets can be revitalized by developing intangible elements such as contents and operational and managerial capacities.

Examining both physical and operational elements of a traditional market, empirical studies delivered somewhat mixed results. Park et al. [13] reported that an investment on supportive facilities, bulletin boards, and pedestrian paths as well as festivals and exhibitions would have positive effects on customer satisfactions. Although the study successfully tested the effects of both physical and non-physical elements, it relied on a single case in Suwon, a satellite city of the Seoul Capital Metropolitan Region.

Kim and Kim [14] found that the economic performance of a traditional market would be enhanced when its physical components are improved in quality. The study also showed that implementing marketing strategies such as circulating discount coupons and vouchers would yield compatible results. Other studies $[18,41]$ have shown that non-physical components such as marketing and operative capacities can be delivered in the form of retail merchant associations. Recognizing this effect, government agencies-including the SEMAS-have suggested traditional markets to form merchant organizations in advance of becoming an eligible recipient of public grant programs [24,43,44]. Jeon [24] specifically suggested that organized efforts through a structured merchant organization are especially effective in improving the performance of a traditional market in urban areas. In addition, in their case study of a Gunsan public market, Kim and Kim [14] analyzed nine variables representing both 
hard and soft components of a market. Among the physical components, transportation convenience (e.g., parking) and building facility conditions were significantly associated with customer satisfaction and among the soft components, product diversity, price level, and service level were found to be significant.

Theoretically, a customer's choice between traditional stores and modernized retail is determined by three factors: the built environmental characteristics (e.g., distance to the store), socioeconomics (e.g., income), and market attributes (e.g., types of products dealt with by the store) [6]. Goldman et al. [6] applied this theoretical concept into his analysis on traditional markets in Hong Kong. The study found that traditional markets are more competitive than modernized retail outlets (e.g., superstores) on perishable goods and foods. In an Israeli community of an Arabian country, customers tend to visit traditional markets to purchase foods that deliver their ethnicity, traditions and religious customs, regardless of their income status. In other words, culture and ethnicity may have played a vital role in preventing superstores from spreading over the country [26]. Likewise, Shim [45] conducted a survey in Anyang and Ji-Dong Markets and reported higher levels of customer satisfaction and intention to revisit among those customers who visited shops selling agricultural products and restaurants in the markets. In addition, several case studies on traditional markets in Seoul (Namdaemun Market, Tongin Market, Gwangjang Market) and in Jangheung city $[17,46,47]$ discovered that specialized restaurants and local produce-in conjunction with supports from the local government, advertisements through social networking service (SNS), and surrounding cultural environments of the district-play important roles in drawing tourists to the markets.

Studies on consumption behaviors suggest that traditional markets should not be considered (or compete) as a substitute for modernized retail. For example, Hong and Kim [48] argued that most customers have already switched their mode of grocery shopping to superstores and supermarkets. Hypermarkets and supermarkets become daily shopping spaces for modern consumers; the trend is predominant and hard to reverse [28,48]. From this perspective, studies suggested traditional markets to position "strategically" as complements—not as substitutes—to superstores or shopping malls by redeveloping themselves to attract customers for socio-cultural activities, sightseeing, leisure, and entertainment [49-51].

As a typical form of modernized retail, shopping malls with mixed tenants and categories have succeeded in attracting customers for a variety of leisure and shopping activities. The retail tenant mix is based on the combination of anchor tenant, food court, and a variety of stores [52], and this strategy is often suggested for traditional markets in transforming their characteristics to capture a wide range of customers who have different purposes [40,53]. Shopping malls have captured a variety of needs and purposes of modern consumers by mixing product categories, through which they developed a new type of consumption space where people can buy, play, and socialize [54-58]. The retail tenant mix has been discussed as an approach to revitalize traditional markets $[40,51,59]$. For example, exploring the determinants of customers' intentions to revisit, Noh and Cho [59] classified traditional markets into two types according to their retail mix and found that customers who used a market comprised of a high mixture of restaurants, eateries, and service stores reported greater satisfaction; their preference in choosing a retail mode were shown to be very similar to those who use shopping malls. Accordingly, the study argued that modern consumers have greater demand for a space where they can shop and be exposed to various leisure opportunities at the same time, and traditional markets can incorporate strategies to respond to such a trend. Likewise, Choo and Kim [16] investigated a sample of 10 traditional markets in Seoul and found strong associations between the customers' intentions to revisit and the markets' experiential elements including the hospitality of the store, uniqueness of the commodity, and excitements embedded in the markets and their ambiences.

According to La Pradelle [21], modern customers use traditional markets for their cultural and social function rather than economic needs. In consideration of the cultural and social importance of traditional markets as a public space, studies [1,25,41,60-63] have attempted to rediscover the traditional markets' role in a modern context and its distinctive elements of place. They found that 
distinctive elements such as humanity, sociality, locality, authenticity, and/or domesticity (feeling at home) make them attractive and are missing in modernized superstores. Modern customers value warmth, friendliness, kindness, and authenticity as the unique sense of place experienced at the traditional retail market [63]. While these studies focused mainly on the socio-cultural aspects of the traditional markets, they also highlighted the importance of the economic vitality of a market as a prerequisite for the facilitation of its socio-cultural vibrancy $[1,2,23]$.

As a whole, much attention has been paid in identifying a traditional retail market's competitiveness against the advancement of modernized retailers and ways to sustain its economic vitality through public policies. However, our knowledge of a traditional retail market is limited in the sense that urban studies on this subject have focused on projecting its distinctive importance as a public space or a tourist attraction (as opposed to modernized retail). Likewise, the competitiveness of a traditional retail market was often defined and assessed with customer satisfaction $[15,28,30,46]$.

On the other hand, traditional retail markets not only create jobs for low-income classes, but also incubate new start-ups $[2,23,35]$. Consequently, the economic performance of a traditional market is linked closely to the local economy. Although a higher level of customer satisfaction is expected to yield a higher rate of customer returns in general, the level of satisfaction assessed from a visitor's shopping experience is not equivalent to the performance of the retailers or the local economy.

Up to this point, academic findings on traditional markets (or marketplaces) focused on understanding the characteristics of the market as an urban space. Meanwhile, empirical studies have depended on case study results or sample surveys conducted only in a small number of markets. An exception was Kim and Kim's 2015 research on traditional markets [14]; they used secondary public data and conducted multivariate analyses to estimate the annual revenue. However, the study analyzed markets located only in small and mid-sized towns and rural areas, excluding those in highly urbanized areas such as Seoul, where $23 \%$ of traditional markets in Korea exist. In addition, the numbers of cases (i.e., sample size) and variables included in their analytical models were limited.

Contrary to the existing (previous) studies, this paper examines traditional retail markets with a (comprehensive) set of variables including indicators representing a market's hard and soft components such as its physical aspects, merchant association, and product lines as well as environmental indicators (e.g., accessibility, competitors, and socioeconomics of the households).

In particular, this paper differs from the previous studies in the following ways: (1) city-wide official datasets were obtained from public institutions in order for the measurement validity and representativeness (the data represented a total of 131 traditional markets all across Seoul); (2) different types of variables were analyzed-from those on market performance and socioeconomics through land use characteristics that were measured at different geographic scales (in a way of identifying the range to which a variable exerts an effect)—and (3) the competitiveness/vitality of a market was evaluated with not only the revenue and number of customers as economic measures, but also the number of blog postings. This can measure the popularity of traditional markets as tourism and leisure destinations and accordingly broaden our insights on their future direction for sustainable development.

\section{Data and Methods}

\subsection{Data}

This study examined cross-sectional data obtained from the SEMAS: the 2015 Current Conditions of Traditional Markets and Stores. As affiliated with the Korean Ministry of Small and Medium Business Administration, the SEMAS administers a comprehensive assessment on the conditions of all traditional markets and small businesses registered across the country. The main purpose of the assessment is to monitor the markets and small businesses supported by national subsidy programs. Since the data provides the basic information on the locations of the traditional markets and a variety of their attributes, this study used its subsample for Seoul. 


\subsection{Sample Construction}

According to the SEMAS, as of 2015, 282 traditional markets (registered, designated, and unregistered) are located across 25 districts in Seoul. From the Seoul subsample of the 2015 SEMAS data, this study chose 131 cases based on the following exclusion criteria. First, non-registered markets were excluded due to insufficient data on these cases. Next, wholesale markets were eliminated because they deal with a few specialized categories (e.g., clothing, medicine, and fisheries, and agriculture). The SEMAS regards a market as a wholesale market if more than half of its shops and vendors are concentrated on a single category. In this sense, the whole sale markets were considered incomparable to the other markets. This selection process constructed a subsample in which only those markets classified as regional or local general markets-according to the SEMAS definition-are included. Lastly, we deliberately excluded those markets that have been transformed into shopping centers. These markets continued being listed as traditional markets because they are engaged in public subsidy programs. However, they have undergone a major reconstruction process and transformed their physical structure. Figure 1 shows the locations of the traditional markets included in the final sample.

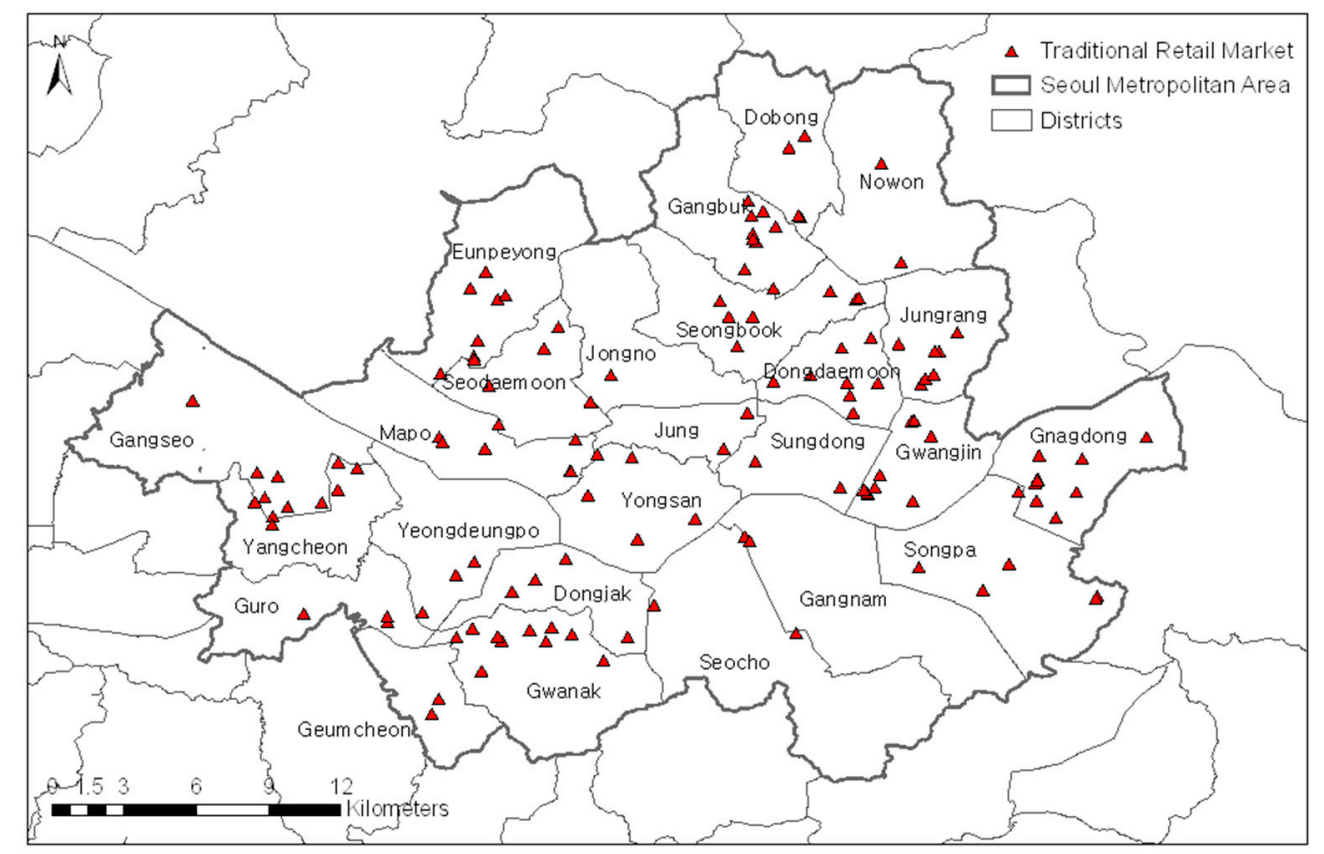

Figure 1. Geographical Distribution of the Samples.

\subsection{Dependent Variables}

This study used regression analysis to estimate the performance of the traditional retail markets in Seoul. Multivariate analyses were employed to capture the relationship between each of the performance measures and independent variables that represent the characteristics of the sampled markets. Through regression analysis, one can estimate the impact of an independent variable while controlling for the effects attributed to the other independent variables [64].

As the dependent variables, three measures were used to represent the annual gross performance of each traditional market: (1) revenue, (2) number of customers, and (3) volume of blog posts uploaded on Internet portals (a proxy for the popularity of a market). The former two variables were estimated through ordinary least squares (OLS) linear regression and the latter one by Poisson-family regression-specifically, negative binomial regression-according to the distribution of this count variable (see Figure 3). 
First, the total sales revenue is the most widely used measure of economic performance of a retail outlet. It is defined as the yearly sum of gross incomes that are generated by the normal sales activities of all stores and vendors in the market. The total revenue of the traditional market generally decreased and showed a sluggish growth over the past several years. The left of Figure 2 shows the gross sales revenue of traditional markets across South Korea compared to that of large grocery chain stores.

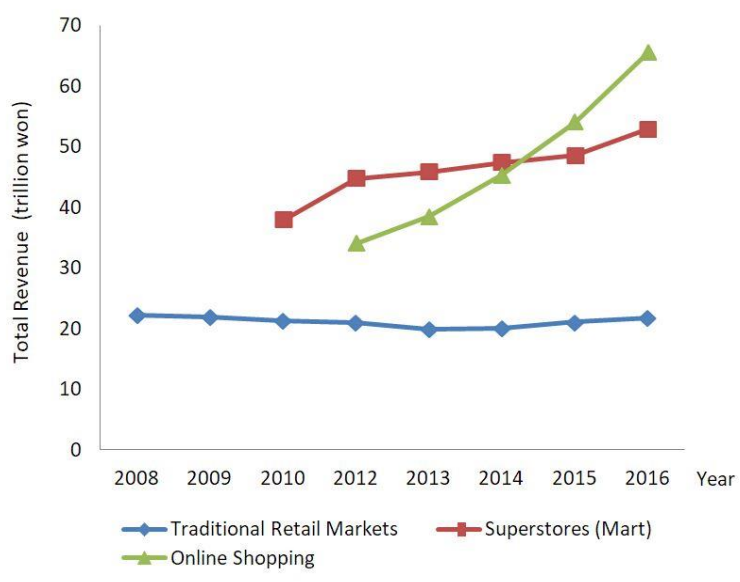

(a)

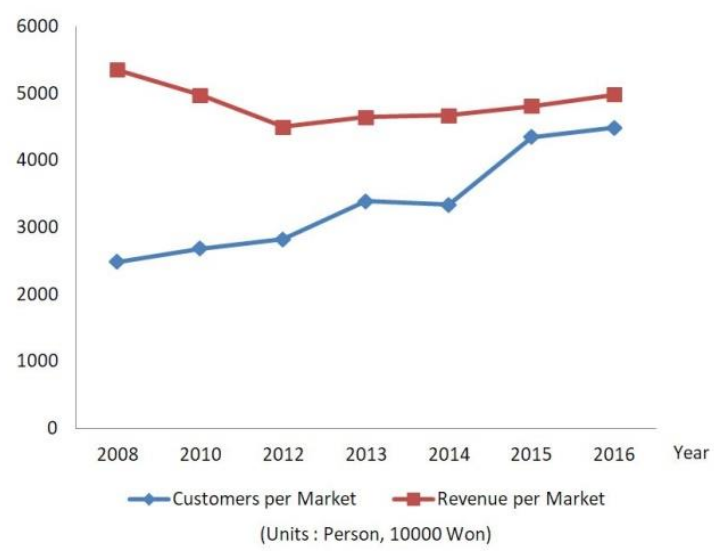

(b)

Figure 2. Annual Total Revenue and Number of Customers of All Registered and Designated Traditional Retail Markets in South Korea: (a) The change in the total revenue is illustrated by retail type; (b) the average total revenue and the total number of customers per market are presented for comparison purposes (edited from SEMAS yearly reports $[65,66]$ ).

Second, the total number of customers refers to the annual sum of daily customers. The data for the total revenue and the number of customers are updated annually by the SEMAS. We chose this indicator as another performance measure because the numbers of total customers are not equivalent to the amount of profits earned, that is, the two indicators are not mutual proxies. The right section of Figure 2 presents that the average revenue and the average number of customers per market differ somewhat. A possible explanation for such a difference is that the type of customers has changed over time and/or items purchased by the customers become more limited due to the expansion of superstores and other modernized retail stores.

Third, we used the number of blog posts on traditional markets to measure the level to which each market is popular as a destination for tourists as well as for customers who visit traditional markets for activities other than grocery shopping (e.g., for socializing, sightseeing, novelty- and variety-seeking purposes, or due to symbolic/aesthetic/cultural attractions to the markets).

Previous studies [20,67-69] found that a variety of human activities are captured in blog texts. On blogs, posts are written in the context of blog writers' daily lives and the contents of the posts are considered genuine and dependable among the users [70]. As such, blogs function as a major information source for tourists, shoppers, and urban consumers (e.g., restaurants and café users). In fact, blog texts have been studied as useful research data in the fields of marketing, hospitality, and sociology [68,70-72].

Since blogs are by and large written by relatively younger customers (e.g., Generation Y and Millennials), Figure 3 implies that a small number of traditional markets succeeded in extending their customer range. Given that traditional markets are usually favored by middle-aged and older customers in South Korea, these markets have successfully expanded their customer ranges through a transition to become popular tourist destinations. 


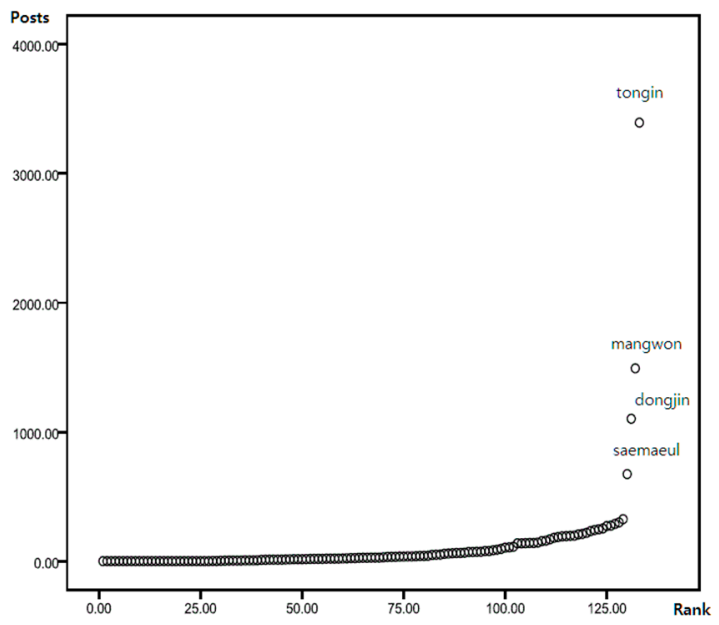

Figure 3. Number of blog posts on tradition retail markets (2015).

This study collected and counted blog posts using programming codes in Python. They were searched on Naver (https: / wwww.naver.com), the most extensively used web portal in South Korea, from 1 January through 31 December 2015. Once blog posts were collected, irrelevant posts, including advertisements, news article copies, and public notes, were removed by using filtering words (see Appendix A). Although not used in this paper, the contents of the blog posts were examined by extracting keywords through text-mining. The text-mining results showed that the blog posts were written mostly about leisure activities; among others, food consumption was the most frequently mentioned activity followed by purchasing and sightseeing (see Appendix B). In this study, a greater number of blog posts indicate more popularity among those who visited traditional markets for leisure and sightseeing purposes.

\subsection{Market Characteristics as Independent Variables}

We identified a total of 31 possible determinants of the performance level of each traditional market. They can be classified into four categories: (1) internal characteristics of the market and its environmental settings in the units of (2) 500-m buffered circle and two administrative zones in Seoul, that is, (3) neighborhood and (4) district. As shown in Figure 1, Seoul has 25 districts comprised of 424 neighborhoods in total.

The regression models included two exposure variables for the standardization of the dependent variables: total number of stores and total floor area (see Table 1). Inasmuch as our dependent variables were gross measures (i.e., annual totals of the revenue, customers, and blog postings), we employed the two variables to control for the effects generated by the number and size of business entities located in each market.

Next, as in Table 1, 18 other variables were employed to account for the operational and the physical/structural (built environment) attributes of the markets. The variables can be further classified into three subgroups: (1) product categories, (2) supporting physical infrastructure, and (3) operational/service components (conditions). 
Table 1. Descriptive statistics.

\begin{tabular}{|c|c|c|c|c|c|c|}
\hline Variables & Descriptions (Unit) & $\mathbf{N}$ & Mean & SD & Min & Max \\
\hline \multicolumn{7}{|c|}{ Dependent Variables } \\
\hline TSalesLg & Total Revenue (log) (won) & 131 & 5.77 & 0.442 & 4.441 & 6.899 \\
\hline TCstmrLg & Total Customers (log) (persons) & 131 & 5.72 & 0.449 & 4.499 & 6.875 \\
\hline TPstng & Total Postings (posts) & 131 & 112.92 & 340.839 & 0 & 3393 \\
\hline \multicolumn{7}{|c|}{ Independent Variables: Exposure } \\
\hline TStoreN & Total Stores & 131 & 96.04 & 75.352 & 13 & 704 \\
\hline TStoreA & Total Floor Area $\left(\mathrm{m}^{2}\right)$ & 131 & 3811.65 & 3030.711 & 256 & 18,687 \\
\hline \multicolumn{7}{|c|}{ Independent Variables: Market-Scale } \\
\hline HrrchD & Hierarchy D: $0=$ lower, $1=$ upper & 131 & 0.13 & 0.337 & 0 & 1 \\
\hline AtomD & Anchor Store D: $0=$ No, $1=$ Yes & 130 & 0.75 & 0.437 & 0 & 1 \\
\hline Dvrst2 & Variety of Product Categories: 0-1 & 130 & 0.34 & 0.118 & 0.13 & 0.87 \\
\hline Rstr & Food Stores/Eateries Ratio: 0-1 & 131 & 0.24 & 0.113 & 0.00 & 0.65 \\
\hline Fresh & Perishable Items Stores Ratio: 0-1 & 131 & 0.12 & 0.140 & 0.00 & 0.79 \\
\hline Cloth & Clothes and Shoes Stores Ratio: $0-1$ & 131 & 0.11 & 0.095 & 0.00 & 0.56 \\
\hline Home & Manufactured Goods Stores Ratio: 0-1 & 131 & 0.21 & 0.135 & 0.00 & 0.68 \\
\hline Srve & Shops for Neighborhood Svc. Ratio: 0-1 & 131 & 0.06 & 0.080 & 0.0 & 0.53 \\
\hline ActvtS & SEMAS Assessment Score & 126 & 52.0 & 9.835 & 23.9 & 76.6 \\
\hline Fclty & Convenience Facilities & 131 & 1.2 & 1.614 & 0 & 8 \\
\hline PR & Advertising Facilities & 131 & 1.2 & 1.361 & 0 & 5 \\
\hline PrkngD & Parking Facility D: $0=$ No, $1=$ Yes & 131 & 0.32 & 0.469 & 0 & 1 \\
\hline AsscD & Merchant Association D: $0=$ No, $1=$ Yes & 131 & 0.75 & 0.436 & 0 & 1 \\
\hline EducD & Merchant Training D: $0=$ No, $1=$ Yes & 131 & 0.37 & 0.484 & 0 & 1 \\
\hline TypeD & Bldg. Structure D: $0=$ Indoor, $1=$ Outdoor & 131 & 0.63 & 0.486 & 0 & 1 \\
\hline Qual & $\begin{array}{l}\text { Bldg. Infrastructure Condition: } 1 \text { (Very Poor) }-5 \\
\text { (Very Good) }\end{array}$ & 131 & 2.99 & 0.890 & 1 & 5 \\
\hline Pdstr & Pedestrian Volume (person): Mkt. Front & 131 & 1371.4 & 1011.428 & 187 & 6271 \\
\hline \multicolumn{7}{|c|}{ Independent Variables: 500-m Radius } \\
\hline Pdstr500 & Pedestrian Volume (persons): $500 \mathrm{~m}$ & 131 & $49,196.0$ & $17,928.41$ & 11,244 & 119,420 \\
\hline MetDist & Proximity to Subway Stat. (m): Shortest Distance & 131 & 452.2 & 336.559 & 33 & 1690 \\
\hline MetRdr & Subway Sta. Users (persons): Nearest sta. & 131 & $1,186,579.0$ & $928,428.80$ & 0 & $4,718,814$ \\
\hline MetN500 & Number of Subway Sta. w/n 500 m & 131 & 0.75 & 0.798 & 0 & 4 \\
\hline BusN500 & Number of Bus Stops w/n 500 m & 131 & 23.8 & 8.506 & 4 & 52 \\
\hline LU500D & Land Use D: $0=$ Residential, $1=$ Mixed & 131 & 0.40 & 0.491 & 0 & 1 \\
\hline Retl500 & Number of Other Retail Businesses & 131 & 492.14 & 261.649 & 130 & 1601 \\
\hline FcltyM 500 & Number of Main Facilities ${ }^{1}$ & 131 & 83.3 & 33.739 & 20 & 200 \\
\hline Empl500 & Number of Employees (persons) & 131 & $21,925.3$ & $12,001.88$ & 3845 & 84,146 \\
\hline BigD & Superstore D: $0=$ No, $1=$ Yes & 129 & 0.50 & 0.502 & 0 & 1 \\
\hline \multicolumn{7}{|c|}{ Independent Variables: Neighborhood (Dong)-Scale } \\
\hline PoorDong & $\begin{array}{l}\text { Low-Income Household Ratio (\% of the Basic } \\
\text { Livelihood Security Recipients) }\end{array}$ & 128 & 140.9 & 71.630 & 16 & 358 \\
\hline MAgeDong & Average Age of Household Members & 130 & 41.2 & 5.132 & 0.70 & 46.0 \\
\hline EmplDong & Employment Density & 128 & 8384.9 & 7922.698 & 386.37 & $50,291.0$ \\
\hline \multicolumn{7}{|c|}{ Independent Variables: District $(G u)$-Scale } \\
\hline PopGu & Population Density & 131 & 7654.22 & 2025.577 & 254.56 & $11,434.21$ \\
\hline EmplGu & Employment Density & 131 & 6669.9 & 4813.669 & 2816.3 & $38,040.7$ \\
\hline BigGu & Retail Superstore Density $\left(\mathrm{m}^{2}\right)$ : floor area & 131 & 0.81 & 0.634 & 0.38 & 5.20 \\
\hline
\end{tabular}

\subsubsection{Product Categories}

Product categories have been reported as a customer's major consideration in planning their shopping trip and in choosing a retail mode $[6,26,53]$. Several studies $[19,26,45]$ showed that traditional markets are more competitive than modernized grocery chain stores in dealing with perishable goods and foods. In the research models, we included five variables to measure the proportions of five major product categories by calculating the ratio of each category's number of stores to the total number of stores (and vendors) opened in the market.

Specifically, stores selling perishables such as agricultural, fish, and meat products were defined as (1) perishable items shops. This study calculated the proportion of the stores selling perishable goods to the total number of stores running in a market. Next, the second category is (2) food stores/eateries ratio, which represents the proportion of the stores and vendors selling local snacks and street/take-out foods in a market. The perishables were differentiated from the processed foods, restaurants, and street 
food vendors because the latter items arguably attract an extended range of customers from distances including both domestic and international visitors seeking experiences and leisure activities besides those visitors who use markets mainly for groceries [22,40,47]. Third, the stores selling manufactured goods were also classified into two variables by product type: (3) stores on clothes and shoes and (4) stores selling all others manufactured goods including home-ware and electronics. Lastly, (5) the shops for neighborhood service represented those facilities including bank branches, medical clinics, and neighborhood beauty salons.

In addition to the five product category variables, two variables were employed to examine the retail tenant mix of product categories and the existence of an anchor store at the market. First, a diversity of product categories in a market may positively influence its economic performance as opposed to concentrating on a few categories. The latter may cause a branding effect by attracting a group of customers who search for a single category in depth [73,74], but this may narrow its customer rage. Instead, the former is likely to lead to an increase in its total revenue by facilitating one-stop shopping, hence extending the market's consumer range. This study used dissimilarity index as a measure of retail tenant mix across nine categories. Ranging from 0 to 1 , the variable represents the level of imbalance among the nine groups: $0=$ a total of nine categories are evenly distributed in size and $1=$ the market is dominated by one category.

Another common retail marketing strategy is to locate an anchor store at the center point. An anchor store is expected to generate a trickle-down effect on its neighboring stores by drawing a relatively large number of customers from distance [51,75]. According to the SEMAS data, supermarkets, specialty shops, and real estate service centers are the examples of the anchor stores placed within traditional markets. This study tested the effects of their existences using a dummy variable.

\subsubsection{Supporting Physical Infrastructure}

At the governmental level, initial efforts to revitalize traditional markets were focused on improving (or modernizing) physical components such as their building infrastructure: roads (path-way surface), pillars, electricity, and roofs. Apparently, the more improved the conditions of these components, the better the overall performance of the markets was expected to be [14], but their effects on a market's economic performance have been debated [27]. Thus, to test this expectation, we included a variable, infrastructure conditions; the data for this variable was measured by the SEMAS on the five-point Likert-type rating scale: $1=$ very poor and $5=$ very good.

In addition, we included three "objective" variables to evaluate the conditions of the infrastructure at a market: number of customer convenience facilities, number of advertising facilities, and type of building structure of the market (indoor vs. outdoor).

Lastly, in terms of the market hierarchy, regional markets are considered to be equipped with better and more physical infrastructure with a greater customer range than neighborhood markets. Previous studies [48] reported that markets on higher hierarchical levels (positions) are more resilient against the advancement of modernized retailers. Thus, we controlled for the possible effects induced from the hierarchical attribute of a market with a dummy variable: $0=$ neighborhood-level and $1=$ regional.

\subsubsection{Organizational/Operational Conditions}

Not only the physical elements, but their operational elements would also contribute to the retail performance of traditional markets. Previous studies [41] highlighted the importance of improving the operational elements of a market because merchants can cooperatively provide superior goods and services by organizing a merchant association or implementing a collaborative strategy; such organizational developments would ultimately increase customers' satisfaction level and their intentions to revisit. In this study, the organizational (operational) elements were measured with three variables: the existence of a retail merchant association at the market $(0=$ no and $1=$ yes), the 
completion of a merchant training program $(0=$ no and $1=$ yes $)$, and the comprehensive assessment scores from the public agent of the SEMAS. Notably, a merchant training program is provided through the Merchant University, delivered by the Ministry of SMEs and Startups to develop a merchant's skills in customer service and marketing [76]. The SEMAS comprehensive assessment score is the total weighted average of the outcome values of multiple evaluation sectors including collaborative marketing efforts among merchants and vendors, their responsiveness to governmental programs, and other managerial skills such as in product display, marketing skills, and sanitation of the products and stores [77].

\subsection{Environmental Characteristics as Independent Variables}

In addition to the physical and operational aspects of a traditional market, its geographical settings may affect its retail performance. Considering the location attributes of a market, this study included environmental variables and measured them in three units of observation (i.e., direct locality, neighborhood, and district), which would accordingly assess each variable's spatial range of influence. In consideration of the fact that the service range of a retail store is 300 square meters in general [12], we operationalized a 500-m buffered zone as the direct locality of a market.

As listed in Table 1, the characteristics of the direct locality of a traditional market were evaluated with nine variables. Most of these variables were retrieved from the Commercial Districts Analysis System Database of the SEMAS, except for data on subway proximity and on the existence of a superstore in proximity. The subway proximity was the network distance to the nearest subway station generated by using online interactive GIS mapping system [78]. Land use, transportation, and socio-demographic characteristics of the neighborhoods and the districts were retrieved from the Statistics Korea (the national agency for managing public statistical indicators and data).

The pedestrian volume was included as an independent variables since a considerable proportion of people visit traditional markets "by chance" or when "passing by the neighborhood" [79]. This study accounted for these casual visitors by including in research models the pedestrian volume variable in two spatial units: (1) in front of the main gate of the traditional market and (2) in its 500-m buffered zone.

Regarding the public transportation systems of the surrounding neighborhood, this study evaluated subway availability (the number of subway facilities in a spatial unit or facility density) [80-82] along with above-stated subway proximity. Since the subway facilities are usually located in urban centers and commercial areas, each of the subway proximity and availability may be a proxy for how a traditional market is close to a neighborhood's commercial areas and an urban center of Seoul. In addition, this study evaluated the daily average subway ridership to consider the hierarchy of the subway station. Lastly, in addition to the subway availability, this study also included the number of subway facilities and the availability of the bus system in the models. Kim and Kim [14] reported that the number of bus stations is positively associated with the total revenue of traditional retail markets (stores); however, they did not consider subway facilities in their OLS regression model because they analyzed markets in small towns and rural areas without subway systems.

According to the household production theory, high-income households are more likely to choose hypermarkets for their grocery shopping in the sense that they can save time and costs in travel. As opposed to small businesses and traditional retail markets, one-stop shopping at hypermarket saves opportunity costs, and higher income households prefer such a mode of retail because they have higher opportunity costs in relation to shopping time, while low-income households have relatively lower opportunity costs to save [6,74]. In this paper, the effect of the household income on the retail performance was estimated at the neighborhood level, using the variable of the proportion of those households that are registered as the Basic Livelihood Security Recipient.

In addition to income, age is considered in this study as a socio-demographic determinant. In general, customers tend to shop at stores run by retailers of a similar age; younger customers are less 
familiar with traditional retail markets, hence, they are less favorable to them in general [54]. At the neighborhood level, this study included the average age of household members in the research models.

Along with the socio-demographics, this study analyzed the effects of three land use variables to reflect the anticipated demand around a market: household density, employment density, and the number of other retail businesses. When offices and businesses are located close to a market, they may benefit from each other (i.e., agglomeration effects) [83,84]. Particularly, a market would benefit from the businesses because of potential customers when they are closely located. Along with the number of retail businesses within the 500-m radius from a market, this study also measured employment density at three different scales (500-m buffer, neighborhood, and district) to check the spatial range of the effect.

Unlike other businesses, superstores have long been regarded as the greatest threat (rival) to traditional markets. However, their negative impact on traditional markets has been reported to be inconsistent [85-88]. As such, in consideration of the possible negative impact of superstores on traditional markets, this study included two variables in the research models. One is a dummy to check the existence of a superstore close to a traditional market, and the other is a continuous variable that measures the superstore density in a district. Arguably, superstores have a larger service range than that captured in the neighborhood boundary, and their effects on other businesses would vary according to the range [89].

\section{Results}

Table 1 shows the list of the research variables and their descriptive statistics. All variables have due variations for inferential statistics. As shown, this study used a total of 35 independent variables. Notably, the maximum number of independent variables depends on the sample size. As a rule of thumb that is frequently referred to, Austin and Steyerberg [90] recently argued that two cases per variable are enough to estimate the regression coefficient, standard error, and confidence interval. Thus, considering its sample size $(n=116)$, this study can include a maximum of 58 variables. Meanwhile, according to Green [91], the sample size of 104 plus the number of independent variables is required for the testing of the individual variable and as a different criterion, Harris [92] suggested that the number of cases should exceed the number of independent variables by at least 50 . Based on any of these two criteria, all 35 variables that were initially considered in this study can be entered into the regression models. (As an exception, Van Voorhis and Morgan [93] recommended a considerably stricter rule: 30 cases per variable. However, for an exploratory purpose of analysis, this study appears to have an appropriate sample size).

The annual totals of the revenue and customers were analyzed with OLS linear regression. By contrast, regarding the number of blog postings, a critical mass of traditional markets had zero values. As shown in Figure 2, this count variable had the Poisson distribution. Between Poisson and negative binomial regression, this study employed the latter model according to Pearson's goodness-of-fit statistic $(=15,174.61(p=0.000))$. In addition, for the alternative negative binomial regression, the likelihood-ratio test of $\alpha=0$ strongly supported negative binomial regression: $\chi \_b a r 2(01)=8952.88$ $(p=0.000)$.

With a growing number of predictors, a regression model tends to provide a better goodness-of-fit. This model fit inflation issue is often raised for exploratory studies-including this particular study - with an extensive set of predictors. Thus, readers are advised to refer to AIC and BIC indices that simultaneously consider the parsimony of a model as well as conventionally used adjusted (pseudo) $\mathrm{R}^{2}$. Notably, this study discusses statistical significance at the $90 \%$ confidence level. In the literature, the confidence levels of $90 \%, 95 \%$, and $99 \%$ are frequently chosen. Although the $95 \%$ confidence level is the most frequent, this study was determined to tolerate a higher significance level as it is an exploratory study conducted in a limited area [94,95].

Table 2 presents the results of the three regression models estimating the relationship between the physical, organizational (operational), environmental attributes (variables) of a market and its 
performance variables evaluated in three different measures. When the results are compared across the models, one can find that a set of similar variables significantly affect the total revenue and the total number of customers. This result may confirm the validity of the outcomes of the statistical models. In other words, a market with a greater number of customers would also earn a higher revenue, and the characteristics between these markets are similar. Specifically, eight variables had a significant effect both on the revenue and the number of customers (the direction $( \pm)$ of the coefficients are indicated in parentheses and were consistent between the two models): the total number of stores $(+)$, the existence of an anchor store (within the market) $(-)$, the ratio of food stores/eateries $(+)$, the ratio of perishable items stores $(+)$, the existence of a merchant association $(+)$, the building infrastructure condition $(+)$, the ratio of low-income households ( - ), and the retail superstore density (of the district) (-).

The results indicate that the higher the ratios of restaurants/eateries and stores selling perishables (e.g., meat, agriculture, and fish), the higher the annual revenue and the number of customers. In addition, a market with an organized entity (the merchant association) would yield higher revenues and attract a greater number of customers as well. Furthermore, the maintenance of the quality of its physical infrastructure was found to be a positive determinant of both of the dependent variables.

By contrast, the two OLS regression models showed that a higher ratio of the Basic Livelihood Security Recipients at the neighborhood level would make a market to yield a smaller amount of revenue and to attract a smaller number of customers. Considering the effect of other retail stores and businesses around the markets, the negative impact of the superstore's density was found to be significant at the district level. Similarly, Gim [80] argued that the availability of a facility (i.e., their density) should be taken into account rather than the proximity (i.e., how close the nearest facility is located) inasmuch as customers tend to choose a particular facility that satisfies their needs. At the district level, the density of superstores negatively affected the total revenue and customer volume. This confirms our initial intuition that the big-box retails have negative impacts on the economic performances of traditional markets and further indicates that these influences are present on the district scale. In this sense, traditional markets should be considered as substitutes for superstores. On the other hand, their competitive relationship was found at the district level, but not in close proximity within the neighborhood range. Consistent with previous studies $[86,88,89]$, the result partially supports the argument that the close proximity between a superstore and retail outlets may generate reciprocal benefits rather than negative effects on the traditional markets' side [89].

Counterintuitively, the presence of an anchor store was found to reduce, not increase, both the revenue and the volume of customers. That is, locating key tenants such as supermarkets, chain stores, and service centers may attract customers to the anchor store, but they barely generate any trickle-down effects to the other stores. In support of this result, the DI index representing the retail category mix in our models turned out to have a positive impact on the number of customers. As shown in these results, thus, strategies to increase the diversity of the nine category assortments would be more desirable for a market to generate a greater revenue rather than locating anchor tenants.

The three variables showed significant effects only on the annual revenue-not on the customer volume; as the number of convenient facilities is smaller, the more a market completes the merchant training program, and the greater the population density of the district, the higher the annual revenue in the market. Notably, the number of customer convenience facilities had a negative effect on the total revenue. A plausible explanation for this result is that the dependent variable (annual revenue) was standardized by the exposure variables; the total area and number of stores were held constant in our regression model, thus, the revenue would be lowered when more spaces were taken by the non-commercial use facilities in a market. As such, at least in the short term, it could be recommended that a market should allocate more spaces to retail stores (sales) in lieu of placing convenience facilities to boost their revenue because these non-commercial spaces do not directly generate profits. In addition, as expected in previous research $[18,41]$, completing a merchant training program (hence, improving sales and customer service skills through educational input) was found to have a positive effect on a market yielding higher revenue. 
Table 2. Ordinary Least Squares and Negative Binomial Regression $(n=116)^{1}$.

\begin{tabular}{|c|c|c|c|c|c|c|c|c|c|c|c|c|c|c|c|c|c|}
\hline & \multirow{2}{*}{ Variables } & \multirow{2}{*}{ Descriptions } & \multicolumn{5}{|c|}{ Model 1 (OLS): Revenue } & \multicolumn{5}{|c|}{ Model 2 (OLS): Customers } & \multicolumn{4}{|c|}{ Model 3 (NB): Blog Postings } & \multirow{2}{*}{ VIF } \\
\hline & & & Coef. & SE & $t$ & $p$ & $\beta$ & Coef. & SE & $\mathrm{t}$ & $p$ & $\beta$ & Coef. & SE & $\mathrm{z}$ & $p$ & \\
\hline \multirow{2}{*}{ Exposure } & TStoreN & Total Stores & 0.003 & 0.001 & 6.21 & 0.000 & 0.605 & 0.004 & 0.001 & 6.85 & 0.000 & 0.612 & -0.004 & 0.005 & -0.82 & 0.410 & 3.51 \\
\hline & TStoreA & Total Floor Area & $8.33 \times 10^{-6}$ & $1.11 \times 10^{-5}$ & 0.75 & 0.456 & 0.055 & $9.55 \times 10^{-6}$ & $1.02 \times 10^{-5}$ & 0.93 & 0.353 & 0.063 & $-6.44 \times 10^{-5}$ & $6.75 \times 10^{-5}$ & -0.95 & 0.340 & 2.01 \\
\hline \multirow{17}{*}{ Market } & HrrchD & Hierarchy D & 0.027 & 0.090 & 0.30 & 0.768 & 0.020 & -0.005 & 0.083 & -0.06 & 0.951 & -0.004 & 0.947 & 0.766 & 1.24 & 0.216 & 1.75 \\
\hline & AtomD & Anchor Store D & -0.139 & 0.071 & -1.96 & 0.053 & -0.133 & -0.113 & 0.065 & -1.74 & 0.086 & -0.108 & 0.114 & 0.579 & 0.20 & 0.844 & 1.70 \\
\hline & Dvrst2 & Variety of Product Categories & -0.425 & 0.265 & -1.61 & 0.112 & -0.113 & -0.420 & 0.244 & -1.72 & 0.089 & -0.111 & 0.493 & 2.161 & 0.23 & 0.820 & 1.84 \\
\hline & Rstr & Food Stores/Eateries Ratio & 0.584 & 0.264 & 2.21 & 0.030 & 0.149 & 0.723 & 0.243 & 2.97 & 0.004 & 0.184 & 0.194 & & 0.09 & 0.928 & 1.69 \\
\hline & Fresh & Perishable Items Stores Ratio & 1.015 & 0.227 & 4.48 & 0.000 & 0.317 & 1.031 & 0.208 & 4.95 & 0.000 & 0.3 & -1.715 & 2.0 & -0.85 & 0.395 & 1.85 \\
\hline & Cloth & Clothes and Shoes Stores Ratio & -0.011 & 0.293 & -0.04 & 0.969 & -0.002 & 0.021 & 0.269 & 0.08 & 0.939 & 0.0 & 4.974 & 2.450 & 2.03 & 0.042 & 1.36 \\
\hline & Home & Manuf. Goods Stores Ratio & 0.330 & 0.226 & 1.46 & 0.148 & 0.092 & 0.131 & 0.207 & 0.63 & 0.528 & 0.0 & -1.334 & 1.586 & -0.84 & 0.400 & 1.45 \\
\hline & Srve & Shops for Neighborhood Svc. Ratio & 0.814 & 0.412 & 1.98 & 0.051 & 0.137 & 0.478 & 0.378 & 1.26 & 0.210 & 0.080 & -4.639 & 2.790 & -1.66 & 0.96 & 1.78 \\
\hline & Actvts & SEMAS Assessment Score & $3.78 \times 10^{-4}$ & $3.35 \times 10^{-3}$ & 0.11 & 0.911 & 0.008 & $5.13 \times 10^{-5}$ & $3.08 \times 10^{-3}$ & 0.02 & 0.987 & 0.001 & 0.049 & 0.026 & 1.84 & 0.066 & 1.96 \\
\hline & Fclty & Convenience Facilities & -0.038 & 0.021 & -1.80 & 0.076 & -0.138 & -0.032 & 0.020 & -1.64 & 0.104 & -0.115 & 0.038 & 0.180 & 0.21 & 0.833 & 2.17 \\
\hline & PR & Advertising Facilities & 0.039 & 0.026 & 1.50 & 0.137 & 0.118 & 0.029 & 0.024 & 1.20 & 0.234 & 0.087 & -0.037 & 0.215 & -0.17 & 0.865 & 2.30 \\
\hline & PrkngD & Parking Facility D & -0.050 & 0.072 & -0.69 & 0.491 & -0.053 & 0.008 & 0.066 & 0.12 & 0.905 & 0.008 & 0.906 & 0.525 & 1.72 & 0.085 & 2.14 \\
\hline & AsscD & Merchant Association D & 0.221 & 0.081 & 2.72 & 0.008 & 0.217 & 0.192 & 0.075 & 2.57 & 0.012 & 0.188 & -0.085 & 0.646 & -0.13 & 0.896 & 2.35 \\
\hline & EducD & Merchant Training D & 0.121 & 0.072 & 1.69 & 0.094 & 0.130 & 0.069 & 0.066 & 1.05 & 0.295 & 0.074 & 0.227 & 0.515 & 0.44 & 0.659 & 2.18 \\
\hline & TypeD & $\begin{array}{l}\text { Bldg. Structure D } \\
\text { Bldr Intrastructure Condition }\end{array}$ & -0.051 & 0.081 & -0.63 & 0.528 & -0.055 & 0.020 & 0.074 & $\begin{array}{l}0.28 \\
278\end{array}$ & 0.784 & & 0.134 & 0.587 & 0.23 & 0.819 & $\begin{array}{l}2.77 \\
159\end{array}$ \\
\hline & $\begin{array}{l}\text { Qual } \\
\text { Pdstr }\end{array}$ & $\begin{array}{l}\text { Bldg. Infrastructure Condition } \\
\text { Pedestrian Volume }\end{array}$ & $\begin{array}{l}0.124 \\
282 \times 10^{-5}\end{array}$ & $\begin{array}{c}0.033 \\
393 \times 10^{-5}\end{array}$ & $\begin{array}{l}3.81 \\
072\end{array}$ & $\begin{array}{l}0.000 \\
0475\end{array}-3$ & $\begin{array}{l}0.250 \\
0.064\end{array}$ & $\begin{array}{c}0.083 \\
519 \times 10^{-5}\end{array}$ & $\begin{array}{l}0.030 \\
361 \times 10-5\end{array}$ & 2.78 & 0.007 & 0.167 & $\begin{array}{l}0.122 \\
295 \times 10^{-4}\end{array}$ & $\begin{array}{c}0.258 \\
284 \times 10^{-4}\end{array}$ & 0.47 & 0.636 & 1.59 \\
\hline & Pdstr & Pedestrian Volume & $2.82 \times 10^{-5}$ & $3.93 \times 10^{-5}$ & 0.72 & 0.475 & 0.064 & $5.19 \times 10^{-5}$ & $3.61 \times 10^{-5}$ & 1.44 & 0.155 & 0.118 & $2.95 \times 10^{-4}$ & $2.84 \times 10^{-4}$ & 1.04 & 0.298 & 2.97 \\
\hline \multirow{10}{*}{ 500-m Buffer } & Pdstr500 & Pedestrian Volume & $-6.16 \times 10^{-7}$ & $2.52 \times 10^{-6}$ & -0.24 & 0.808 & -0.025 & $-3.28 \times 10^{-6}$ & $2.32 \times 10^{-6}$ & -1.42 & 0.160 & -0.131 & $-1.28 \times 10^{-5}$ & $1.73 \times 10^{-5}$ & -0.74 & 0.459 & 3.79 \\
\hline & MetDist & Proximity to Subway Stat. & $3.27 \times 10^{-5}$ & $1.18 \times 10^{-4}$ & 0.28 & 0.783 & 0.022 & $-7.05 \times 10^{-5}$ & $1.09 \times 10^{-4}$ & -0.65 & 0.518 & -0.048 & $-1.33 \times 10^{-4}$ & $8.27 \times 10^{-4}$ & -0.16 & 0.872 & 2.38 \\
\hline & MetRdr & Subway St. Users & $-2.90 \times 10^{-8}$ & $3.23 \times 10^{-8}$ & -0.90 & 0.372 & -0.060 & $-9.41 \times 10^{-9}$ & $2.97 \times 10^{-8}$ & -0.32 & 0.752 & -0.019 & $1.88 \times 10^{-7}$ & $2.38 \times 10^{-7}$ & 0.79 & 0.430 & 1.67 \\
\hline & MetN500 & Number of Subway Sta. & -0.037 & 0.051 & -0.73 & 0.468 & -0.057 & -0.015 & 0.047 & -0.33 & 0.742 & -0.024 & 0.415 & 0.388 & 1.07 & 0.284 & 2.25 \\
\hline & BusN500 & Number of Bus Stops & 0.002 & 0.003 & 0.45 & 0.651 & 0.028 & 0.002 & 0.003 & 0.76 & 0.447 & 0.042 & 0.032 & 0.026 & 1.24 & 0.214 & 1.36 \\
\hline & LU500D & Land Use D & 0.100 & 0.076 & 1.32 & 0.191 & 0.109 & 0.096 & 0.070 & 1.37 & 0.174 & 0.104 & 0.062 & 0.599 & 0.10 & 0.918 & 2.51 \\
\hline & Ret1500 & Number of Other Retail Bus. & $-7.55 \times 10^{-6}$ & $2.05 \times 10^{-4}$ & -0.04 & 0.971 & -0.004 & $1.98 \times 10^{-4}$ & $1.89 \times 10^{-4}$ & 1.05 & 0.298 & 0.106 & $1.91 \times 10^{-3}$ & $1.39 \times 10^{-3}$ & 1.37 & 0.171 & 4.53 \\
\hline & FcltyM $\sim 500$ & Number of Main Facilities & $1.66 \times 10^{-3}$ & $1.21 \times 10^{-3}$ & 1.38 & 0.172 & 0.126 & $1.14 \times 10^{-3}$ & $1.11 \times 10^{-3}$ & 1.03 & 0.308 & 0.086 & -0.006 & 0.009 & -0.65 & 0.514 & 3.09 \\
\hline & BigD & Superstore D & -0.043 & 0.061 & -0.70 & 0.485 & -0.047 & -0.006 & 0.056 & -0.11 & 0.913 & -0.007 & -1.132 & 0.416 & -2.72 & 0.006 & 1.67 \\
\hline & Empl500 & Number of Employees & $1.66 \times 10^{-7}$ & $4.12 \times 10^{-6}$ & 0.04 & 0.968 & 0.004 & $-2.29 \times 10^{-6}$ & $3.79 \times 10^{-6}$ & -0.61 & 0.547 & -0.053 & $-3.33 \times 10^{-5}$ & $3.15 \times 10^{-5}$ & -1.06 & 0.289 & 3.40 \\
\hline \multirow{3}{*}{ Neighbor-hood } & MAgeDong & Avg. Age of Residents & -0.017 & 0.021 & -0.82 & 0.413 & -0.064 & -0.018 & 0.020 & -0.93 & 0.355 & -0.066 & -0.199 & 0.175 & -1.14 & 0.255 & 2.23 \\
\hline & Poor500 & Low-Income Household Ratio & $-9.82 \times 10^{-4}$ & $4.70 \times 10^{-4}$ & -2.09 & 0.040 & -0.152 & $-9.41 \times 10^{-4}$ & $4.32 \times 10^{-4}$ & -2.18 & 0.032 & -0.145 & 0.003 & 0.004 & 0.73 & 0.467 & 1.96 \\
\hline & EmplDong & Employment Density & $9.25 \times 10^{-7}$ & $4.64 \times 10^{-6}$ & 0.20 & 0.842 & 0.015 & $-1.98 \times 10^{-6}$ & $4.27 \times 10^{-6}$ & -0.47 & 0.643 & -0.031 & $3.30 \times 10^{-5}$ & $3.66 \times 10^{-5}$ & 0.90 & 0.367 & 1.96 \\
\hline \multirow{3}{*}{ District } & PopGu & Population Density & $3.27 \times 10^{-5}$ & $1.56 \times 10^{-5}$ & 2.09 & 0.040 & 0.148 & $2.05 \times 10^{-5}$ & $1.44 \times 10^{-5}$ & 1.43 & 0.157 & 0.092 & $-5.00 \times 10^{-5}$ & $1.33 \times 10^{-4}$ & -0.38 & 0.707 & 1.84 \\
\hline & EmplGu & Employment Density & $-3.48 \times 10^{-6}$ & $1.47 \times 10^{-5}$ & -0.24 & 0.813 & -0.031 & $7.71 \times 10^{-7}$ & $1.35 \times 10^{-5}$ & 0.06 & 0.955 & 0.007 & $2.41 \times 10^{-4}$ & $1.25 \times 10^{-4}$ & 1.93 & 0.053 & 6.16 \\
\hline & BigGu & Retail Superstore Density & -0.238 & 0.108 & -2.20 & 0.031 & -0.270 & -0.289 & 0.099 & -2.91 & 0.005 & -0.327 & -1.130 & 0.827 & -1.37 & 0.172 & 5.56 \\
\hline \multirow[t]{2}{*}{ Constant } & & & 5.297 & 0.973 & 5.44 & 0.000 & . & 5.571 & 0.895 & 6.23 & 0.000 & . & 8.427 & 7.564 & 1.11 & 0.265 & \\
\hline & & & \multicolumn{5}{|c|}{$\begin{array}{c}\mathrm{F}(35,80)=8.27(p=0.000) \\
\mathrm{R}^{2}=0.7835, \text { Adj } \mathrm{R}^{2}=0.6888 \\
=0.25313, \mathrm{AIC}=0.339, \mathrm{BIC}=-412.930\end{array}$} & \multicolumn{5}{|c|}{$\begin{array}{c}\mathrm{F}(35,80)=10.31(p=0.000) \\
\mathrm{R}^{3}=0.8186, \mathrm{Ajj} \cdot \mathrm{R}^{2}=0.7392 \\
\text { RMSE }=0.23267, \mathrm{AIC}=0.171, \mathrm{BIC}=-423.477\end{array}$} & \multicolumn{4}{|c|}{$\begin{array}{l}\text { LR chi2 }(35)=57.77(p=0.009) \\
\text { McFadden's pseudo } \mathrm{R}^{2}=0.048, \text { Adj. pseudo } \mathrm{R}^{2}= \\
-0.027, \mathrm{ML} \mathrm{R}^{2}=0.392 \text {, Cragg and Uhler's } \mathrm{R}^{2}= \\
0.392 \text {, } \\
\text { Log likelihood }=-569.17001 \\
\text { lnalpha }=0.801(\mathrm{SE}=0.131) \text {, alpha }=2.227(\mathrm{SE}= \\
0.292), \mathrm{AIC}=10.589, \mathrm{BIC}=800.835\end{array}$} & \\
\hline
\end{tabular}

${ }^{1}$ Variables that are significant at the $90 \%$ confidence level are in bold. 
Lastly, this study measured employment density at three geographic scales. Among them, the employee density at the district level was found to significantly increase the revenue of a traditional market. In other words, traditional markets are affected by the conditions of their surrounding business agglomerations that are greater than the approximate neighborhood [96]. The result implies that it may be necessary to strategically broaden the range of policy inputs at the administrative level, in order for a traditional market to attract customers from a broader range.

While a similar set of variables were significant in predicting the revenue and customer volume, almost none of the variables had a significant effect on the variation of the blog postings. Simultaneously, most variables significant in the blog posting model turned out to be meaningless in predicting the revenue and the number of customers of the markets. The only exception was the ratio of neighborhood service shops. The variable affected the total revenue as well as the total postings, however, the directions of its impacts were opposite for the two dependent variables. While the ratio of neighborhood service shops was positively associated with the annual revenue, it had a negative effect on the volume of blog posts.

The effect of the variable of the neighborhood service shops was negative in relation to the volume of blog posts, probably because the shops are mostly banks, medical clinics, pharmacies, and beauty shops [76] that generally serve residents in the neighborhood. Accordingly, if a market allocates more spaces to these service shops, it is likely that the market is considered more suitable for customers who intend to visit from the neighborhood for their daily needs rather than for those who come for sightseeing and leisure activities.

On the other hand, the volume of blog posts was positively associated with the existence of parking facilities, and district-level employment density, SEMAS assessment score, the ratio of clothes and shoes stores (relative to the ratios of perishable items stores, manufactured goods stores, and neighborhood service stores). First, compared to other categories, clothes and shoes stores can attract window shoppers [97] who are likely to post photos and writings on their blogs. Unlike the total revenue and customer volume, variations in the volume of blog posts were related to the SEMAS assessment score, a proxy for the overall management quality of a market; as described earlier, it represents the overall service, marketing, and operative conditions of a market.

Lastly, the employment density of the district increased blog postings. This result indicates that a market with a greater number of blog posts is more likely to be located in the urban center where jobs and businesses agglomerate and a variety of activities occur. Such an environmental setting increases the chance for a market to be exposed to a greater number of people with a variety of consumption purposes, including leisure.

On the other hand, the location of a superstore near a traditional market posed a negative impact on the volume of blog postings. This result may be attributed to the general location of a superstore; it is usually in a superblock near residential areas with high household density, for the maximum household grocery shopping demand [98]. Such residential settings are likely neither to attract visitors from outside nor to encourage them to write and upload a blog post about the place. In addition, a traditional market surrounded by a predominantly residential use may not be used as a leisure/tourist destination. That is, blog posts are likely to increase in number when a market is located in urban centers (with a high employment density), as discussed earlier, but less likely in dense residential areas favored by superstores.

\section{Discussion and Implications}

In an attempt to revitalize traditional markets and to keep their functions sustainable, researchers and practitioners have developed a variety of urban policies and subsidy programs [23,27]. However, their effectiveness has been questioned in many respects [7,27]. Especially, traditional markets and marketplaces have been considered "marginal" in urban policies, thus "little experiences" were accumulated on this topic until now [2,99]. Likewise, in South Korea, many blueprints have been drawn to revitalize traditional markets, but our knowledge on traditional markets is not enough to 
generate further plans for their economic vitalities over modern retails. In spite of growing attention on topics about tensions between modernized retail and traditional markets, academic investigations on factors influencing their performances have not been extensively conducted yet. In this sense, this paper aimed to examine the factors by predicting the level of performances of the traditional markets. In particular, this study empirically analyzed the characteristics of the traditional market (and the effectiveness of the governmental supports) through OLS and negative binomial regression.

First of all, the outcomes suggested that the public investments in the physical infrastructure of the markets have been an appropriate way to improve their economic performances (revenue and customer volume). In conjunction with Kim and Kim [14] (who found a similar result from small towns and rural areas), this study found that the modernizing efforts and the public investments on the maintenance of the physical conditions of the markets induced positive effects on the economic performances. They turned out to be one of the most salient factors contributing to the economic performances of the markets. This study also confirmed the significant relationship between the revenue and merchants' enhanced capacity through public programs (i.e., Merchant University). Furthermore, out statistical models verified the effect of an operative/organizational entity of the merchants to be positive, through which higher economic performances would be expected as opposed to those without such an organized unit $[6,41,85]$.

Higher performances may have been led by greater investments from the private sector on the physical infrastructure of a traditional market. This would consequently result in a greater level of economic sustainability and vitality $[100,101]$. Nonetheless, the findings of this study imply that a public agency is an appropriate entity that can initiate a regeneration project for deteriorated markets by investing in their basic infrastructure and operative/organizational capacities. Directing public investments onto the basic infrastructure could yield higher economic performances, which may attract future investments from the private sector.

Regarding product categories, the results of our analysis demonstrated that the retail category mix plays a vital role in improving traditional markets' economic performance. Along with the findings from the previous studies $[6,19,26,102]$, we found that the ratios of stores selling perishable goods and the ratio of restaurants and street food vendors were significant in explaining variations in the revenue and the number of customers. In additon, our analytical findings were particularly supportive of increasing the mix of different categories of stores rather than launching a few anchor stores within a market.

The economic performance of a traditional market was also affected by its environmental characteristics. The results from this study showed that a market in a neighborhood populated with households in higher income range is likely to yield greater revenue and attract more customers. Studies on retail modernization $[74,85]$ argued that high-income households prefer shopping at superstores in which they can minimize their opportunity cost for shopping while low-income households are less likely to shop at superstores. In our analyses, however, the ratio of low-income households (i.e., Basic Livelihood Security Recipients) in the neighborhood was associated negatively with the economic performances of the traditional markets. This result could be explained by the limited purchasing power of the recipients of the government's social security grants. Unlike the positive effects of other retail stores and businesses around the markets, the negative impact of the superstore's density was found to be significant at the district level.

Recent studies $[21,22,25,50,51,63]$ attempted to reinterpret the quality of a traditional market as a socio-cultural space. This paper empirically analyzed the socio-cultural popularity of a market with the volume of blog posts uploaded on the Internet. The outcomes showed that the popularity is significantly affected by the organizational (operational) and the environmental characteristics around the markets. According to the results, those characteristics that were significant in the blog posting model entirely differed from the significant factors in the models of the annual revenue and the annual customer volume. The result indicates that a market recognized as a popular tourist destination on the SNS is not necessarily profitable in financial terms. Hence, more attention should be 
paid to this mismatch when a strategy is deliberated to transform a market into a leisure space and tourist attraction.

Notably, the ratio of clothes and shoes stores tend to increase the volume of blog posts, rather than that of restaurants, food vendors, and eateries, which has been highlighted in previous studies [46,47, 63,103 ] as a main attraction of traditional markets. This might suggest that what initiates the "word of mouth" is not the volume of those restaurants, eateries, and street food vendors, but the quality and the distinctiveness of the products they sell. Supposedly, as mentioned in a previous study [103], a small number of specialty stores with unique tastes, materials, or authentic images catch the attention of the visitors who upload blog posts on their SNS. Regarding the retail mix, however, this study used the density and the diversity of the categories; hence, further studies are called for to capture the quality aspects such as the uniqueness and experiential factors.

On the other hand, the blog post model found that the number of posts is associated with the existence of parking facilities. Previously, Noh and Choi [59] argued that those who visited traditional markets for multiple purposes tended to highly value the existence of parking and convenience facilities and the overall quality/ambience of the market. Arguably, these multi-purpose visitors come from a more distant area and spend a longer time at the market [40,59]. Hence, from the results of the blog model, one can suspect that blog writers may have mostly visited traditional markets for such multiple purposes including leisure, sightseeing, and socializing.

To keep an old market sustainable, policy makers should keep finding strategies to improve its physical conditions and to develop organizational/operative components. Regarding the transition of a traditional market into a leisure and tourist destination, the findings of this paper showed that popular markets frequently mentioned on the Internet do not share many characteristics in common with those markets characterized by economic vitality. Although this study measured and tested the effect of leisure consumption with the volume of blog posts, it did not encompass possible effects induced from variations in the type of customers regarding their socio-demographic, motivational, and cognitive and perceptual traits (e.g., objective/actual vs. subjective/perceived density) [104]. Further studies are recommended to consider the characteristics of the consumers and their consumption activities, preferably in empirical models using primary data through a sample survey. This study employed multivariate analyses to identify factors on the performance variables regarding the traditional retail markets. No causal explanations of the results should be implied, however, in the sense that the analyses are based on cross-sectional observations in 2015 [105]. Further studies are recommended upon the availability of any time-series data.

Author Contributions: Y.-M.Y. designed the research, collected the data, and wrote the paper; T.-H.T.G. analyzed the data and revised the paper.

Conflicts of Interest: The authors declare no conflict of interest.

\section{Appendix A}

This study removed blog postings with terms in Table A1, and found a total of 13,709 posts to be appropriate for the analysis. 
Table A1. Exclusion criteria.

\begin{tabular}{ccc}
\hline Phone Numbers/Addresses & Advertisements & Others \\
\hline $02-$ & Sublet & \\
$010-$ & Apartments & "reports that ... " \\
$070-$ & One room & "stated that ..." \\
Email & Move in & XXX reporter \\
Contact & Down payments & Public garage (bus) \\
Address & Nail (shop) & "nearby (the market)" \\
"please call" & Driver (call) & "across from (the market)" \\
$: \ldots, \odot, \bullet \star \star \star \star$ & Advertisement & \\
\hline
\end{tabular}

\section{Appendix B}

Table A2 shows that bloggers who visited traditional markets have written most frequently about food consumption and eating-out, followed by price and shopping as well as sightseeing experiences.

Table A2. Keywords by word frequency (semantic differentials) ${ }^{1}$.

\begin{tabular}{ccccccc}
\hline Ranks & Verbs $^{2}$ & Freq. & Ratio & Adjectives $^{2}$ & Freq. & Ratio \\
\hline 1 & Eat (1) & 38,691 & 0.0136 & Tastes good (1) & 18,231 & 0.0064 \\
2 & Buy (2) & 8064 & 0.0028 & Good (0) & 17,137 & 0.0060 \\
3 & Take (photos) (3) & 6064 & 0.0021 & Inexpensive (2) & 3427 & 0.0012 \\
4 & Like (0) & 5753 & 0.0020 & Tasty (1) & 2397 & 0.0008 \\
5 & Make (0) & 5595 & 0.0020 & Neat (0) & 1927 & 0.0007 \\
6 & Sightsee (3) & 3718 & 0.0013 & Spicy (1) & 1728 & 0.0006 \\
7 & Sell (2) & 3017 & 0.0011 & Happy (0) & 1563 & 0.0005 \\
8 & Meet (3) & 2033 & 0.0007 & Low-price (2) & 1524 & 0.0005 \\
9 & Wait (0) & 2846 & 0.0010 & Abundant (1) & 1407 & 0.0005 \\
10 & Drink (1) & 1856 & 0.0007 & Warm (0) & 1374 & 0.0005 \\
11 & Fry (1) & 1752 & 0.0006 & Fun (3) & 1302 & 0.0004 \\
12 & Get (=buy) (2) & 1718 & 0.0006 & Fresh/alive (1) (2) & 1270 & 0.0005 \\
13 & Purchase (2) & 1608 & 0.0006 & Full (1) & 1113 & 0.0004 \\
14 & Enjoy (3) (1) & 1488 & 0.0005 & Chili (spicy) (1) & 1067 & 0.0004 \\
15 & Pick (2) & 1285 & 0.0005 & Expensive (2) & 1026 & 0.0004 \\
16 & Stir fry (1) & 1170 & 0.0004 & Exciting (3) & 778 & 0.0003 \\
17 & Go find/visit (3) & 1169 & 0.0004 & Eccentric (3) & 764 & 0.0003 \\
18 & Taste (1) & 1123 & 0.0004 & Alive (fresh) (1) (2) & 718 & 0.0003 \\
19 & Walk around (3) & 1074 & 0.0004 & Peculiar (3) & 629 & 0.0002 \\
20 & Play (3) & 1020 & 0.0004 & Chewy (1) & 599 & 0.0002 \\
\hline
\end{tabular}

${ }^{1}$ Adopted from a previous research and edited for the purpose of this paper [20]. ${ }^{2}(0)=$ neutral; (1) = food consumption, (2) shopping and price, and (3) sightseeing experiences.

\section{References}

1. Watson, S. The magic of the marketplace: Sociality in a neglected public space. Urban Stud. 2009, 46, 1577-1591. [CrossRef]

2. Morales, A. Marketplaces: Prospects for social, economic, and political development. J. Plan. Lit. 2011, 26, 3-17. [CrossRef]

3. National Institute of Korean History. From Marketplace to Mart: Transformation of Modern Market Economy; Doosan Dong-A: Seoul, Korea, 2007.

4. Alex, M.M. Regulatory responses to large-format transnational retail in South-East Asian cities. Urban Stud. 2007, 44, 357-379.

5. Jackson, J. Drive in culture of contemporary america. The crabgrass frontier: The suburbanization of the United States. In The City Reader; Legates, R., Ed.; Stout: New York, NY, USA, 1985.

6. Goldman, A.; Ramaswami, S.; Krider, R.E. Barriers to the advancement of modern food retail formats: Theory and measurement. J. Retail. 2002, 78, 281-295. [CrossRef] 
7. Gonzalez, S.; Waley, P. Traditional retail markets: The new gentrification frontier? Antipode 2013, 45, $965-983$. [CrossRef]

8. Kim, K.-J. Causes and consequences of urban decline in Korean cities. J. Korean Urban Geogr. 2010, 13, 43-58.

9. Chae, S.H.; Koo, H.K. The decline processes, responses, and the future of traditional markets: The case of nambu market in Jeonju city. Comp. Cult. Stud. 2015, 21, 87-131.

10. Korean Chain Stores' Association. The Yearbook of Retail Industry; Korean Chain Stores Association Press: Seoul, Korea, 2016.

11. Woo, H.J. Study on Cultural Policies to Vitalize Traditional Retail Markets; Korea Culture and Tourism Institute: Seoul, Korea, 2008.

12. Ma, S.Y.; Ahn, J.P. The Meaning of Superstore Regulation and Cooperative Developments with Small and Mid-Sized Retails; Gyeongnam Development Institute: Changwon, Korea, 2012; pp. 1-35.

13. Park; Cheong, H.; Koo; Ja, H. Analysis of the impact of culture promotion activities on social capital formation and market competitiveness of the traditional market-A comparative view of routine merchant activities. J. Urban Des. Inst. Korea Urban Des. 2014, 15, 123-136.

14. Kim, J.-S.; Kim, J.-S. A study on influential factors on traditional markets' revenue. Mod. Soc. Adm. 2015, 25, $1-18$.

15. Kim, K.-S. Study on the influence of service quality on customer satisfaction and revisiting intention in traditional markets of susan's downtown area. J. Korea Plan. Assoc. 2009, 44, 235-244.

16. Choo, M.J.; Kim, K.K. The study of developing cultural service quality on customer satisfaction in traditional market. J. Korea Cult. Ind. 2013, 13, 97-104.

17. Kim, D.-H. Place recognition of traditional market customers and policy directions for revitalizing communities. J. Econ. Geogr. Soc. Korea 2014, 17, 517-537.

18. Song, K.S.; Beom, S.K. The study of customer-oriented merchant organization of conventional market. J. Distrib. Manag. Res. 2011, 14, 5-27. [CrossRef]

19. Park, B.D.; Noh, J.K. Consumer-recognized competitive advantage factors of conventional market and its policy implications. J. Distrib. Res. 2007, 12, 17-48.

20. Yi, Y.-M. The Role of Leisure Consumption and the Characteristics of Place Experienced in Seoul's Traditioanl Retail Markets. Dissertation, School of Environmental Studies, Seoul National University, Seoul, Korea, 2017.

21. La Pradelle, M. Market Day in Provence; University of Chicago Press: Chicago, IL, USA, 2006.

22. Zukin, S. Consuming authenticity: From outposts of difference to means of exclusion. Cult. Stud. 2008, 22, 724-748. [CrossRef]

23. IMMB. Urban Markets: Heart, Soul and Motor of Cities; Institute Municipal de Mercat de Barcelona (IMMB): Barcelona, Spain, 2015.

24. Jeon, C.-J.; Cheong, C.-M. Analysis of characteristics according to the form of merchant organization in traditional market. Resid. Environ. J. Resid. Environ. 2014, 12, 287-295.

25. Mele, C.; Ng, M.; Chim, M.B. Urbanmarkets as a 'corrective' to advanced urbanism: The social space of wet markets in contemporary Singapore. Urban Stud. 2015, 52, 103-120. [CrossRef]

26. Goldman, A.; Hino, H. Supermarkets vs. Traditional retail stores: Diagnosing the barriers to supermarkets' market share growth in an ethnic minority community. J. Retail. Consum. Serv. 2005, 12, 273-284. [CrossRef]

27. Lee, D.-H.; Lee, Y.-S. A study on the effect of government's traditional retail and periodic market policies on revitalization of market: Focused on traditional retail and periodic markets in the urban areas of Daegu and Daejeon. J. Ind. Econ. Bus. 2013, 26, 2337-2360.

28. Kim, H.J.; Cho, K.Y.; Lee, S.W. A study on the choice factors and possibility of traditional market-Compared to other competing markets based on consumer behavior analyses. J. Distrib. Res. 2010, 15, 81-102.

29. Kim, P.J.; Kim, K.J.; Sung, N.G.; Yoon, M.G. A study on the customers' awareness for modernizing the facilities of traditional market. J. Distrib. Sci. 2009, 7, 55-70.

30. Kim, H.R.; Lee, J.J. Comparative study on tourist attractiveness of culture tourism oriented traditional marketplace Int. J. Tour. Hosp. Res. 2011, 25, 63-77.

31. Park, C.H.; Koo, J.H. Analyzing the factors of revitalization for physical improvement and cultural support activities on the traditional market-A case study on motgol traditional market from the merchants point of view in su-won. J. Korea Plan. Assoc. 2013, 48, 121-137.

32. Park, S.H.; Sun, I.S. Study on vitalization of inje traditional market-Focusing on e-business. J. e-Bus. Stud. 2013, 14, 135-152. 
33. Lee, M.S.; Lim, C.S. The meaning of results of business performance through activation project for bong-pyeong traditional market -focusing on design standardization of facilities. J. Korean Soc. Des. Cult. 2015, 21, 451-461.

34. Zhu, S.; He, C. Moving beyond Anglo-American economic geography: The significance of non-anglo-American model. Int. J. Urban Sci. 2018, 1-7. [CrossRef]

35. Morales, A. Public markets as community development tools. J. Plan. Educ. Res. 2009, 28, 426-440. [CrossRef]

36. SEMAS. Assessment of Traditional Retail Market Support Project (2015); Small Enterprise and Market Service: Daejeon, Korea, 2015.

37. Boarnet, M.; Crane, R. The influence of land use on travel behavior: Specification and estimation strategies. Transp. Res. A 2001, 35, 823-845. [CrossRef]

38. Gim, T.-H.T. A meta-analysis of the relationship between density and travel behavior. Transportation 2012, 39, 491-519. [CrossRef]

39. Kim, W.H.; Kim, H. A local economic development strategy: Evidence from traditional maket districts. Venture Manag. Study 2013, 16, 1-18.

40. Park, K.A. Applying retail entertainment for a competitive strategy of local retailers. J. Korean Reg. Dev. Assoc. 2005, 17, 273-292.

41. Yang, S.K. Designing strategic management and implementation system of the merchant association organization in a traditional market place: Focused on "b" traditional market. Korean Rev. Corp. Manag. 2014, 5, 93-114.

42. Guimarães, P. Revisiting retail planning policies in countries of restraint of Western Europe. Int. J. Urban Sci. 2016, 20, 361-380. [CrossRef]

43. SEMAS. Market Marketing Supports, Jeon-Tong Shi-Jang Tong Tong. Available online: http:/ / www.sijangtong.or.kr/nation/support/mkCommonMarketing.do?menu_type_a=A\&menu_ cms=\&menu_id=251200 (accessed on 14 May 2018).

44. Vale, L.J. Cities of stars: Urban renewal, public housing regeneration, and the community empowerment possibility of governance constellations. Int. J. Urban Sci. 2018, 1-30. [CrossRef]

45. Shim, W.S. The study of relations between customer satisfaction by purchasing favored products and revisit intention at traditional markets space. J. Korea Cult. Ind. 2013, 13, 97-104.

46. Yoon, S.H.; Park, J.Y. The impact of tourist attractiveness of traditional markets on their evaluation. Korean J. Tour. Res. 2009, 24, 57-73.

47. Lee, J.H. Success factors for developing urban and rural traditional marketplace as a tourist attraction: The case of Seoul Gwangjang market and Jangheung Toyo (Saturday) market. J. Econ. Geogr. Soc. Korea 2014, 17, 366-384.

48. Hong, S.-W.; Lee, J.-H. Markets of Korea, Focusing on Periodical Markets; Minumsa: Seoul, Korea, 1992.

49. Choi, M.J.; Park, H.; Sohn, S. Effects of urban entertainment center on commercial market structure at regional and local levels-The case of 'time square' mixed-use shopping mall in Seoul. J. Urban Des. Inst. Korea Urban Des. 2012, 13, 93-107.

50. Kim, A.K.; Yoo, C.K.; Lee, H.C. Valuing sociocultural functionality of traditional market: A study of traditional markets in the Seoul metropolitan area. J. Tour. Sci. 2012, 36, 53-68.

51. Jung, Y.S.; Seo, Y.G. Entertainment Shopping Mall: Prospects; Sansumg Economic Research Institute: Seoul, Korea, 2001.

52. Gerbich, M. Shopping center rentals: An empirical analysis of the retail tenant mix. J. Real Estate Res. 1998, 15, 283-296.

53. Yuo, T.; Crosby, N.; Lizieri, C.M.; McCann, P. The Management of Positive Inter-Store Externalities in Shopping Centres: Some Empirical Evidence; University of Reading: Reading, UK, 2003.

54. Boedekoer, M. New-type and traditional shoppers: A comparison of two major consumer groups. Int. J. Retail. Distrib. Manag. 1995, 23, 17-26. [CrossRef]

55. Holbrook, M.B.; Hirschman, E.C. The experiential aspects of consumption: Consumer fantasies, feelings, and fun. J. Consum. Res. 1982, 9, 132-140. [CrossRef]

56. Kabadayi, S.; Paksoy, B. A segmentation of Turkish consumers based on their motives to visit shopping centres. Int. Rev. Retail Distrib. Consum. Res. 2016, 26, 456-476. [CrossRef]

57. Bloch, P.H.; Ridgway, N.M.; Dawson, S.A. The shopping mall as consumer habitat. J. Retail. 1994, 70, $23-42$. [CrossRef] 
58. Wakefield, K.L.; Baker, J. Excitement at the mall: Determinants and effects on shopping response. J. Retail. 1998, 74, 515-539. [CrossRef]

59. Noh, K.H.; Choi, C.H. Research on Selection Elements of Traditional Markets Affecting Re-Visit Intentions: Tenant Mix; Korea Distribution Association: Seoul, Korea, 2015; pp. 179-196.

60. Hunt, A.R. Consumer interactions and influecnes on farmers' market vendors. Renew. Agric. Food Syst. 2006, 22, 54-66. [CrossRef]

61. Somer, R.; Herrick, J.; Sommer, T.R. The behavioral ecology of supermarkets and farmers' markets. J. Environ. Psychol. 1981, 1, 13-19. [CrossRef]

62. Mcgrath, M.A.; John, F. Sherry, J. An ethnographic study of an urban periodic marketplaces: Lessons from the midville farmers' market. J. Retail. 1993, 69, 280-319. [CrossRef]

63. Yolande, P.-S.; Daniel, H. Authenticity with a bang: Exploring suburban culture and migration through the new phenomenon of the richmond night market. Urban Stud. 2013, 52, 538-554.

64. Urdan, T.C. Statistics in Plain English, 3rd ed.; Routledge, Taylor \& Frnacis Group: New York, NY, USA, 2010.

65. SEMAS. Actual Conditions of the Traditional Market and Store 2015; Small Enterprise and Market Service: Daejeon, Korea, 2015.

66. SEMAS. Actual Condition of the Traditional Market and Store 2016; Small Enterprise and Market Service: Daejeon, Korea, 2016.

67. Volo, S. Bloggers' reported tourist experiences: Their utility as a tourism data source and their effect on prospective tourists. J. Vacat. Mark. 2010, 16, 297-311. [CrossRef]

68. Bing, P.; Tanayama, C.; Crotts, J.C. Travel blogs and the implications for destination marketing. J. Travel Res. 2007, 46, 35-45.

69. Li, X.; Duan, B. Organizational microblogging for event marketing: A new approach to creative placemaking. Int. J. Urban Sci. 2018, 22, 59-79. [CrossRef]

70. Lee, S.L.; Yoon, H.H.; Young, N.K. Blogs in the restaurant industry: Consumer usage motivation and service quality perception. Korean J. Hosp. Tour. 2010, 19, 273-287.

71. Akehurst, G. User generated content: The use of blogs for tourism organisations and tourism consumers. Serv. Bus. 2008, 3, 51. [CrossRef]

72. Karaosmanoğlu, D. Authenticated spaces: Blogging sensual experiences in Turkish grill restaurants in London. Space Cult. 2013, 17, 224-238. [CrossRef]

73. Brown, S. Retail location theory: The legacy of Harold Hotelling. J. Retail. 1989, 65, 450-470.

74. Hanson, S. Spatial diversification and multipurpose travel: Implications for choice theory. Geogr. Anal. 1980, 12, 245-257. [CrossRef]

75. Finn, A.; Louviere, J.J. Shopping center image, consideration, and choice: Anchor store contribution. J. Bus. Res. 1996, 35, 241-251. [CrossRef]

76. SEMA. Commercial District Information System; Small Enterprise and Market Agency (SEMA): Daejeon, Korea, 2016.

77. Agency of Traditional Market Administration. Assessment Analysis of Traditional Retail Market; Agency of Traditional Market Administration: Seoul, Korea, 2013.

78. Daum. Daummap. Sky View 2015. Available online: http://map.daum.net/ (accessed on 6 August 2016). (In Korean)

79. Lee, M.J. A Study on Place Brand Identity Design for Vitalization of Traditional Market-Around the Moran Traditional Market; Ewha University: Seoul, Korea, 2014.

80. Gim, T.-H.T. The relationship between land use and automobile travel utility: A multiple indicators multiple causes approach. Transp. Res. Part D 2015, 41, 188-204. [CrossRef]

81. Jang, S.; An, Y.; Yi, C.; Lee, S. Assessing the spatial equity of Seoul's public transportation using the Gini coefficient based on its accessibility. Int. J. Urban Sci. 2017, 21, 91-107. [CrossRef]

82. Ramani, T.L.; Zietsman, J. Sustainable transportation-Alternative perspectives and enduring challenges. Int. J. Urban Sci. 2016, 20, 318-333. [CrossRef]

83. Kim, G.; Kim, K.-M. The impact of firm size and industrial diversity on office market volatility. Int. J. Urban Sci. 2018, 1-14. [CrossRef]

84. Kim, G.H.; Park, I.K. Agglomeration economies in knowledge production over the industry life cycle: Evidence from the ict industry in the Seoul capital area, South Korea. Int. J. Urban Sci. 2015, 19, 400-417. [CrossRef] 
85. Dunkley, B.; Helling, A.; Sawicki, D.S. Accessibility versus scale: Examining the tradeoffs in grocery stores. J. Plan. Educ. Res. 2004, 23, 387-401. [CrossRef]

86. Haltiwanger, J.; Jarmin, R.; Krizan, C.J. Mom-and-pop meet big-box: Complements or substitutes? J. Urban Econ. 2010, 67, 116-134. [CrossRef]

87. Michael, J.H.; Stanley, R.K.; Lee, C.S. Mom-and-pops or big box stores: Some evidence of walmart impact on retail trade. Econ. Dev. Q. 2012, 26, 311-320.

88. Seo, Y.G.; Han, K.D. The impact of large discount stores on the retail trading area in Seoul metropolitan area: A spatial-econometric analysis. J. Channel Retail. 2015, 20, 47-64.

89. Seo, Y.G.; Choi, C.H. Analyses on the Retail Regulation Using Big-Data; Korea Distribution Association: Seoul, Korea, 2017; pp. 28-48.

90. Austin, P.C.; Steyerberg, E.W. The number of subjects per variable required in linear regression analyses. J. Clin. Epidemiol. 2015, 68, 627-636. [CrossRef] [PubMed]

91. Green, S.B. How many subjects does it take to do a regression analysis. Multivar. Behav. Res. 1991, 26, 499-510. [CrossRef] [PubMed]

92. Harris, R.J. A Primer of Multivariate Statistics; Academic Press: New York, NY, USA, 1985.

93. VanVoorhis, C.W.; Morgan, B.L. Understanding power and rules of thumb for determining sample sizes. Tutor. Quant. Methods Psychol. 2007, 3, 43-50. [CrossRef]

94. Priest, S.H. Doing Media Research: An Introduction; Sage: Thousand Oaks, CA, USA, 2009.

95. Wimmer, R.D.; Dominick, J.R. Mass Media Research: An Introduction; Wadsworth: Belmont, CA, USA, 2013.

96. Drennan, M.P. Do agglomeration economies decay over short distances? Are they stable in the face of shocks? Evidence from Manhattan. Int. J. Urban Sci. 2018, 22, 1-16. [CrossRef]

97. Yuo, T.; Crosby, N.; Lizieri, C.M.; McCann, P. Tenant Mix Variety in Regional Shopping Centres: Some UK Empirical Analyses; University of Reading: Reading, UK, 2004.

98. Maruyama, M.; Wu, L.; Huang, L. The modernization of fresh food retailing in china: The role of consumers. J. Retail. Consum. Serv. 2016, 30, 33-39. [CrossRef]

99. Fainstein, S.S. Cities and diversity. Urban Aff. Rev. 2005, 41, 3-19. [CrossRef]

100. Lejano, R.P.; Kan, W.-S. Seeing urban regeneration through an institutional lens: Toward a new contextualism. Int. J. Urban Sci. 2015, 19, 257-268. [CrossRef]

101. Jayantha, W.M.; Chun Ming, C. The effect of urban redevelopment on retail shopping property values: A case study in Hong Kong. Int. J. Urban Sci. 2015, 19, 379-399. [CrossRef]

102. Goldman, A. The transfer of retail formats into developing economies: The example of china. J. Retail. 2001, 77, 221-242. [CrossRef]

103. Zukin, S. Naked City: The Death and Life of Authentic Urban Places/Sharon Zukin; Oxford University Press: New York, NY, USA, 2010.

104. Kim, Y. Impacts of the perception of physical environments and the actual physical environments on self-rated health. Int. J. Urban Sci. 2016, 20, 73-87. [CrossRef]

105. Kim, M.; Gwak, I.; Koh, J. The strategies of advanced local spatial data infrastructure for Seoul metropolitan government. Int. J. Urban Sci. 2018, 1-17. [CrossRef]

(C) 2018 by the authors. Licensee MDPI, Basel, Switzerland. This article is an open access article distributed under the terms and conditions of the Creative Commons Attribution (CC BY) license (http://creativecommons.org/licenses/by/4.0/). 